\title{
Social Media Techno-Discursive Design, Affective Communication and Contemporary Politics
}

\author{
Majid KhosraviNik ${ }^{1}$
}

Received: 6 February 2018/Accepted: 31 March 2018/Published online: 18 April 2018

(C) The Author(s) 2018

\begin{abstract}
The paper examines the intersection of technological design of Social Media communication, the notion of post-politics-affective turn in contemporary (Western) societies and the rise of populism as a trend in political communication. Following on conceptualizations for a Social Media approach to a broadly defined critical discourse studies framework (KhosraviNik, in: Kalyango and Kopytowska (eds) Why discourse matters: negotiating identity in the mediatized world, Peter Lang, New York, 2014, in: Flowerdew and Richardson, Routledge handbook of critical discourse studies, Routledge, London, 2017b), the paper attempts to integrate discussions on affective nature of communication in participatory web ecology and consequences of algorithmic regimentation of meaning bearing resources (e.g., news and entertainment) on Social Media. Issues around quality and distribution of digital discursive practices and their relations to traditional perceptions of rational politics, within the internalised ethos of visibility-as-legitimacy, are critically elaborated and examined. While the rise of right wing populism (e.g., Trump presidency, Brexit vote) should primarily be explicated within qualities of the context on the ground, i.e., the deliberate and well-orchestrated misplacement of real grievances in society through discursive operation and manipulation (KhosraviNik in Insight Turk 19(3):53-68, 2017a), it is equally important to critically elaborate the function and consequences of (digital) media practices as a main part of this socialization context. The overall argument here is that the hyper-normalization and triumph of neo-liberal rationality together with new media technological affordances, design and requirements have created a momentum for the growth of haphazard
\end{abstract}

Majid KhosraviNik

Majid.khosravinik@newcastle.ac.uk

1 Digital Media and Discourse Studies Media, Culture, Heritage, School of Arts and Cultures, Armstrong Building, University of Newcastle, Newcastle upon Tyne NE1 7RU, UK 
populist politics, i.e., the valorization of affective relevance over rational significance.

Keywords Populism · Algorithms · Social Media politics · Digital discourse $\cdot$ Critical discourse studies

The paper examines the links between technological design of Social Media communication, the notions of post-politics-affective turns in contemporary (Western) societies and the rise of populism as a trend in political communication. Populism has been discussed in terms of its discursive content, anti-establishmentarianism, and its affective rather than argumentative characteristics. In other words, it has been studied both as political/ideological content as well as a style of communication. Right wing populism has particularly been on the rise in the West in recent years (Richardson 2013; Wodak et al. 2013) evidenced by electoral gains in France and Germany, Brexit vote and the presidency of Donald Trump in the US. As far as the politics on the ground is concerned, the rise of populism is rooted in hyper-normalization of offshoots of neo-liberal life order (KhosraviNik 2017a), e.g., extreme individualism, competitive (rather than deliberative) persuasion and foregrounding of relatability over rationality. In political communication, this translates to rise of personality politics, triumphant of affect over argumentation and reduction of democratic project to media(tised) performance. In fact, there is a strong suggestion that we are now in a post-politics, post-ideology era, i.e., grand narratives of politics have lost credibility and resonance.

In line with the promotional mantra of Social Media, i.e., the democratization of access, the current political discourses maintain an appeal to some form of (caricature) democratic practice along the lines of claims to empowerment of the 'ordinary citizens', re-connection with politics, grass-root mobilization, etc. Incidentally, these constitute the core characteristics of new digital media technologies as well which work with the logic of regimes of popularity building through engagement of prosumers (Ritzer and Jurgenson 2010). The appeal of affective political engagement and the rise of Social Media personality politics are, on the one hand, predicated on internalization of the equation: visibility/popularity is legitimacy (derived from accumulated symbolic power, i.e., power is legitimacy) and, on the other hand, works as a revolt against the perceived monolithic nature of traditional mass media/politics. Both these elements overlap with the populist vociferous claims of revolting against the media and political establishments. The design values and processes at work in Social Media technologies, their political economic model, their starting assumption of post-ideological status of contemporary societies and obsoleteness of critical structural politics are constitutively aligned with promoting an affective-driven, anti-establishment, anti-elite/expert, everyday/banal politics. In a similar vein, the extreme individualization and the corporate algorithmic manipulation of news and information pave the way for normalization of a populist perception of public communication and collective identity-in political as well as all other domains. 
The algorithmic surveillance of Social Media is not an ideological machine in a traditional sense, i.e., it appears to be neutral, automatic and machine controlled. It aspires to claim that there is no human interference in fine grain regimentation of content catered for millions of individual prosumers. This works within the frame and contributes to the legitimacy of post-politics, post-ideology arguments, especially in Media and Technology research approaches. This paper attempts to understand the link between the contemporary politics, new media technologies and their impacts on social understanding of traditional politics as a realm of rationality and enlightenment. Hyper-normalization and triumph of neo-liberal rationality in late modern societies and new media affordances have created a momentum for the growth of haphazard populist politics in every sense. Social Media at the age of behavioral advertising are the epitome of preference of affective relevance over rational significance. Trump performance in the US is a prime example of this trend, not only for the content of his populist right wing views and the typical strategic misplacements of working class grievances (KhosraviNik 2017b), but also because he has successfully reduced the entirety of political practice to a form of obsessive and whimsical Social Media practice.

The essence of politics in modern time, i.e., in post-enlightenment era, is (aspiring to) rationality and deliberative argumentation. The historical antecedent of such strong adherence to objective rationality in modern western philosophy could be traced to the reactions against the monopoly of church and religion in the Middle Ages who would habitually employ affective means to control masses (Papacharissi 2015: 11). This is also linked to an established orientalist trope, which presupposes that western mentality is driven by rationality in thought hence argumentation versus the essential emotionality of Eastern subjects/thought. Many western thinkers have based their social, political and cultural conceptualization on an inherent priority of the rational over the affective. This is the presupposed assumption in construction of entire modern polity as well as all various aspects of political structure and relations of democratic understanding of legitimacy and power. This remains the constant driving aspirational impetus in the face of various forces, which do impact the processes adversely and sway it from the ideal functioning of democratic process including major obstacles posed by the political economic order and increasing normalization of market-based rationality. In the meantime, politics has always been understood as both argumentative content as well as style of communication. This is essentially because politics is about persuasion and persuasion naturally pertains to the questions of what (is being communicated) as well as how (it is being communicated) as previously argued in critical discourse studies inter alia (KhosraviNik 2010, 2015a, b). It is also a fact that certain styles of political communication are more attuned to specific political tendencies, e.g., the links between authoritarianism and populism. In the same vein, right wing populism discourses are characterized by a set of common and recurring discursive strategies, albeit in varying degrees of intensity and scale. Firstly, there is the call for a swift and radical shift from a globalization rationale towards a national and nativist politics. This discursive strategy criticizes the normalized economic politics in the west, i.e., economic liberalism, free movement of capital and labor, and deregulation of financial markets-even though, all these are usually reduced to 
an anti-immigration rhetoric in populist discourse (KhosraviNik 2017a; Marsdal 2013).

Social Media technologies have affected norms of political communication in general and political activism in particular. Now, ordinary users can be part of production, consumption and distribution of content with few or no barriers in the form of traditional gate-keeping practices (KhosraviNik 2014, 2017b). With an oversimplified take on the democratization project, the perception of free access has come to be celebrated as a new frontier for democratic circulation of forms of media content; nevertheless, the potentials of the participatory web in civil, political and social mobilization cannot be categorically dismissed. It is a fact that various groups of ordinary to professional text producers, i.e., bloggers, followers, raters, sharers, likers, as well as traditional journalists, form nodes in an information environment with the potential to organize themselves for various progressive aims. This is not only about transferring content and values per se, but it is about being a site for formation and substantiation of these values, information and worldviews that is discourse (KhosraviNik 2017b). New Media technologies and communicative affordances continue to impact social and political fabrics of societies in (sometimes radically) different ways. Specifically in the context of the Middle East, with (largely) restricted public spheres, the communicative affordances of Social Media have provided opportunities for new forms of citizen activism, construction of alternative identities and deliberations despite the contentious relations of political regimes with the new technology (KhosraviNik and Zia 2014; KhosraviNik and Sarkhoh 2017; KhosraviNik and Kelsey forthcoming). The new technologies have (arguably) empowered ordinary civilians to engage in political and cultural communications and to contribute to expression, formation and dissemination of discourses away from (usually closed) official channels (KhosraviNik and Zia 2014).

Despite the crucial differences in social fabrics and political practices in global contexts, the breeding ground, characteristics and discursive strategies of populist nationalist discourses have striking similarities. In essence, populist nationalist discourse pivots around a real or constructed problem in the social, economic and political status quo. It revolves around discursive construction of a homogenously perceived Self, e.g., Us (the British) versus a homogenously perceived other, e.g., Them (the immigrants, Muslims or by extension EU nationals). Such discourses often fill the gap created by the public's disenchantment with official politics (Wodak and KhosraviNik 2013) while presenting themselves as the indigenous, socially relevant, and righteous alternative to worldviews of the (constructed) establishment. Populist rhetoric is overtly preoccupied with the notion of (re)gaining the (lost) power to actualize a romanticized perception of the past. Trump's vote was partly due to a perception of difference, which, as mentioned before, harvested the outcome of a deliberately misplaced real grievance, orchestrated through a discursive operation and manipulation. The trend towards unquestionable capitalist rationale as the only norm and viable option of governance is also infused and relegated to all the other aspects of live worlds of citizens. This is where the style, dynamic and logics of competition, economic derive and extreme individualism are taken up in provisions of goods and services and even worse, it permeates into life 
domains which had not previously been viewed as a realm of neo-liberal subjugation, e.g., education, health care and life experience. This overwhelming individual marketing approach dismantles society as a collective and when it hits the domain of politics, it replaces facts with validation of favorable opinion. ${ }^{1}$

The hyper-normalization of a neo-liberal life order has translated itself into approaches in political science and cultural studies which have started to do away with radical critic and turned into approaches which claim to pay attention to microlevel analysis of political communication, e.g., the rise of personal politics and individualistically oriented studies on behavior and affect theory. Despite the fact that there are also critical works within this paradigm, a lot of these approaches do not require or have the inclination to critically engage with the macro-structural issues. Macro-structural considerations would consider questions such as why people act the way they do, or why personality and media management of public faces are increasingly becoming more important than the policy and rational deliberation, why the electorates are weary of big politics discussions and young generations are disillusioned with politics, why large populations see politics as irrelevant to their lives and why sensitivities and public knowledge around democratic structure, values, rights are dwindling, why university students do not show significant interest in understanding the basics of democracy or the need for structural critique?

The de-politicization of communication as politics is also a dominant trend in increasing digital participatory platforms. Social Media presented a shift in communication dynamic, i.e., amalgamation of mass and interpersonal communication which has resonated suitably with the train of scholarly thought in affect studies and their conceptualization. For many proponents of such affective turn in social sciences, the 'turn to affect becomes a decisive shift away from current conceptions of critical theory, away from research based on discourse and disembodied talk and texts, towards more vitalist, 'post-human' and processedbased perspectives' (Wetherell 2012: 3). The argument is that modern societies have started to show uneasiness against grand narratives, extreme objectivity in reporting human experience. Consequently, there is a shift in the foundational assumption that politics is concerned with argumentative content and rational discourse. Most of these trends have been afforded by mass communicative technologies in a range of their textual practices from for example BBC's approach in reporting news to a range of entertainment programs. This is similar to notion of first-person media in reference to the rise of reality TV. Similar argument can be put forward in explaining the blogging explosion in early years of millennium and the subsequent changes in digital content production afterwards. It is also a valid point to note that while deliberation and rationality has been the canonical elements of political debate, democracies have been and continue to be 'messy affairs that are driven by aspirations of rationality, caught up in the daily mise-en-scene of ethos, pathos and logos' and that citizens' 'typical daily responses to political developments are a mix of emotion with fact-informed opinion' (Papacharissi 2015: 26). In any case, it is

\footnotetext{
1 See Donald Trump's comments on what he calls 'alternative facts' https://www.theguardian.com/usnews/2017/jan/22/donald-trump-kellyanne-conway-inauguration-alternative-facts.
} 
given now that the bulk of Social Media spaces are essentially affective communicative contexts with the centrality of sharing and connection. The research shows that there is very little argumentative content even when Social Media are appropriated for serious political causes (KhosraviNik and Zia 2014). This is not to say that Social Media communication does not contain, allude to or draw on any argumentative train of thought (topoi) but that there is little or no argumentative content resembling a productive deliberation. Critical discourse analysis/studies as an established critical approach focused on communication content as well as contexts of production and consumption (Wodak and Meyer 2016; KhosraviNik $2017 \mathrm{~b}$ ) is predicated on the premise to attempt to explain how meaning bearing content and behavior are used to create consent or political views. As such, it is only prudent for the approach to integrate approaches in studying the affects/emotions in its argumentation analytical models (Reisigl and Wodak 2016; KhosraviNik and Unger 2016). Nevertheless, the affective turn in its strong conceptualization 'involves more than adding emotions to the inventory of social research topics. It signifies a more extensive ontological and epistemological upheaval, marking a moment of paradigm change' (Wetherell 2012: 3) which in effect, with the exception of what can be categorized as critical affective social studies (e.g., Pedwell 2014; Ahmed 2014), defines itself in contrast to discourse-based studies albeit by viewing discourse within an essentially poststructuralist frame, i.e., not necessarily CDA per se. The extreme affective conceptualization shies away from notions such as critique, ideology and shades of social constructivism to the advantage of a de-politicalized, super-localized analysis. This is not to cast away the potential of affective analysis in attempting to understand how people are moved, and what attracts them and more importantly 'how social formations grab people/ how do the roller coaster of contempt, patriotism, hate and euphoria power public scenes' (Wetherell 2012: 2) which are the crucial aspects of contemporary societies and their behavior (see Wodak et al. 2013). Yet, in their backlash against social constructivism, there remains little room to conceptualize power in social formations as power is, in essence, about discourse (KhosraviNik 2014). As far as this view is concerned, any political matter, be it big $\mathrm{P}$ politics or small $\mathrm{P}$ political, i.e., personal is political, is about power. It is about resisting, engaging, challenging a social formation, a normalized identity; a discourse. Psychological analyses of emotions and affects within an extreme individualistic ontology would not lend themselves easily to conceptualization of the collective, unless they are merged with critical social theory.

The relevance and usefulness of affective analysis should be acknowledged, not because it is the most recent 'turn' in cultural studies and/or social sciences but in that it is attending to aspects of research theorization which relates to the way contemporary societies are behaving politically and more importantly the way Social Media communication has come to either impact the society in that direction or be a symptomatic realization of such change in itself. I approach this from a practical point of view and the way it can contribute in understanding of what is going on in the political debates, actions and democratization project as a whole, within a socially oriented, critical analysis of communication which is CDS to me (KhosraviNik 2017b). However, the mere fact of change in theoretical approach for 
the sake of change is obviously not ground breaking in and by itself. In other words, defining affect as something which is merely just not discourse is hardly usefulthat is, if the research is socially committed.

For a Social Media space, discourse, emotive and the action, i.e., discursive practice (actions of digital marks including) should all be considered together. In traditions of classic discourse approaches, language in and within itself gets priority whereby the rationality and argumentative powers are foregrounded as the main power to persuasion and resonance. This is why there is substantial development of models and tools for analyzing argumentation, fallacies and critical engagement with the degree and quality of rationality in the language use. In the context of digital media technologies, the argumentative content is less central compared to the affective content. Therefore, persuasiveness is more sought after at the triangle of discourse, digital action and the affective state of the individual users. At the interface of participatory web affordance and the user, users have the (perception of) chance of being able to act completely individualistic and are encouraged to prioritize their affective moods, e.g., rage, fear, etc. while in the past these affective qualities of individuals would be filtered, controlled and moderated by various systems of mass media gate-keeping. For example, newspapers would not trust and rely on a non-professional individual's (perhaps one-sided and misguided) assertions and would tend to evaluate the argumentative value and content whereas, in Social Media, such an individual would see no barrier for not only expressing themselves but also gaining credibility through popularity of expressions of their argumentatively incoherent but affectively loaded and strong emotive proposition. Coherence is after all a cognitive disposition as far as the audience is concerned. This is exactly why notions of discourse are important. Discourse is what gives coherence to seemingly fragmented expressions. Discourse is the scaffolding for scattered subjective utterances. In this sense, Social Media platforms not only empower and validate individual's emotive understanding of the affairs but also encourage a dynamic of communication that rewards such behavior with a form of perceived validation.

The post-ideological, post-politics ethos is a dominant trend in Social Media research and theorization. Notions like participation, democratization, and individualism are appropriated, perhaps not even deliberately, to discuss a utopian context of communication brought about by digital affordances. Influential sociological analysis of the impact of Social Media postulates that we have now entered a form of socialization called network society which 'present a qualitative change in human experience' (Castells 2009: 509). Participatory culture is the term Jenkins puts forward to conceptualize the amalgamation of users, audiences, consumers and fans in creation of cultural content. Papacharissi argues that networked digital structures of expression of connection are overwhelmingly characterized by affects and uses the term 'networked publics' as 'publics that are restructured by networked technologies and, therefore, simultaneously are (1) the space constructed through networks technologies and (2) the imagined collective that emerges as a result of the intersection of people, technology and practice (2015: 39).

The affective characteristics of Social Media communication are both a reflection of the change of interest in society in terms of the shift to value first-person media as 
well as being the effect of the way the Social Media technologies are structurally designed. The users' engagement with Social Media technologies seem to occur in a multi-layered collapsed context (Boyd 2008). This affords endless opportunities for the users' affective performance to appeal to audiences or textual consumers who may have not even been envisaged at the initial state of triggering communication. What follows from this is the tendency to emphasize the affective-subjective content of the communicative from one hand and the use of provocation as a way to make one's performance more authentic and real-much similar to the way reality is constructed in reality TV. It is also not entirely wrong to consider affective communication as a form of political expression. 'Affect conveys the intensity with which an opinion is felt, and when expressed, it can intensify the sense of empowerment experienced by the individual releasing the thought, emotion, or act to the public (Papacharissi 2015: 113-114). Even though it is not necessarily deliberative, it can be potentially a powerful political act. Much similar to earlier works in feminism and gender identity, 'affective gestures infuse the story telling of the self with emotive impressions that enhance performances of the self but may also entrap the self in a continuous loop of (mediated) affect' (Papacharissi 2015: 114). In essence, the contentious argument here is that political discourse should not be viewed, considered and evaluated only by the degrees the communication can contribute to deliberation and to the extent Social Media spaces can be deemed as part of public sphere in its classic understanding. But that affective expression is also political because it relates to power and empowerment of the individual. 'Style is performance and performance is power' while in the meantime, 'claims to power are performed' (Papacharissi 2015: 114). It is sensible to view affective expressions as part of political discourse not (just) because these are affective publics but (also) as an outcry of marginalization process that the overwhelming global normalization of neo-liberalism has caused. Capitalism has always had strong scaffolding rationality whereby the values, norms and logics of market are presented and inculcated as not only reasonable but as the only way of envisaging the life world, e.g., the notions of economic development, competition and increasing corporatization of social life and commodification of products, service and life experiences. This macro logic has been hegemonic and invisibly enforced everywhere. This could explain the empowerment process of affective expressions and doing away with the usual overwhelming rationality. At the political level, such affective tendency is only craved in the context that there is strong but incoherent grievances in society in a way that the available normal pubic sphere does not provide suitable platforms for such expressions. This could also explain the anti-intellectual anti-science and in short anti-rationality revolt in recent elections in the UK and USA (KhosraviNik 2017a). This takes us back again to qualities of the wider society or thick context (Couldry 2012) and in fact relates to traditional social issues of class and identity politics. It is apt to argue that any attempt in theorization of affective communication as political would inadvertently take us back to social context and critique in one way or another. De-politicalized, descriptive and superlocalized approaches which advocate a post-politics context for the contemporary era are mainly derived (and contribute to) the understanding that within a normalized economically colonized political sphere nothing can/should/does 
change; hence, engagement with politics in that sense is a moot endeavor. The process of normalization of post-political context is both a top-down macro and bottom up micro process. The post-politics actively denies that the real politics is about policy, argumentation and overarching principles and happily reduces it to media appearance, likeability, psychological connection and relatability in the context that media industry vigorously continues to make advances in colonizing the entirety of official politics. One driving force and culmination of such postideological manipulation in practice are reflected and constituted in the logics and dynamic of interaction on Social Media and participatory web.

Social Media are being used for a plethora of everyday uses and with increasing penetration both in terms of the number of users and depth of engagements. There is obviously a substantial entertainment aspect to the use of digital media. While the big $\mathrm{P}$ politics and structural debates around it have not really benefited from these spaces, i.e., in terms of enhancing the quality of political debate and deliberation, the politics as everyday practice has been hugely impacted by Social Media (Zayani 2015). Entertainment industry had already been working with regimes of rating, popularity and competition as their canon of business practice before Social Media. As such, Social Media everyday politics and political engagement have also been influenced and in fact structured around similar frames. It is only ironic that the current president of the most powerful country in the world is a former TV personality obsessed with rating and winning by popularity metrics. One would not refer to the conducts of a given entertainment business as populist when it aspires to get higher rating through any means available including extreme displays of affective expressions and affective connections, etc. However, in politics that would be characterized as populist. The reason is simply the fact that politics has traditionally been defined as a realm of arguments, rationality and very calculated decision making rather than emotionality. So it is not too far-fetched to consider communication on Social Media as populist in essence and influenced by business model. Populism in politics is the realm of media savvy political performers who make colorful claims for grass-root mobilization. Incidentally, media performance, the claim to empowerment of ordinary citizens, re-connection with politics, grassroot mobilization all constitute the core claimed characteristics of new digital media technologies which work with the logic of regimes of popularity building through 'likes', 'shares' and 'followers', etc. Personality politics on Social Media not only feeds into a highly simplified equation of popularity as legitimacy but at the same time acts as a revolt against the perceived monolithic nature of traditional mass media and grand discourses/rationalities. In contrast to rigidity of mass media in terms of their monopoly over discursive power, the nature, location and dynamic of discursive power in Social Media or broadly speaking participatory web are fluid, changeable, and circular (KhosraviNik 2017b; Unger et al. 2016) in a way that users are at the same time, producers, consumers and distributors of the content. Although the utopian hopes for enhancement of real public deliberation via the Social Media and democratization of public sphere have not materialized, these platforms can still play a significant role for niche politics and non-mainstream representations (Copsey 2003). The fact remains that given the nature of populism as a style of communication, the new digital participatory technology is an apt space for 
construction, promotion and dissemination of such politics. This is not to say that the new communication technologies of participatory web have caused the current shift to right wing populism. The shift has its own roots in practical democratic deficit, i.e., socio-political contexts of relevant societies. Nonetheless, the values and processes at work in Social Media spaces, the political economy of platforms, and their assumption of post-ideological era and obsoleteness of critical politics are in line for promoting an affective-driven, anti-establishment, and fringe politics. Such politics is not built upon argumentation, i.e., rational deliberation in Habermasian sense but it is largely based on affective communication which foregrounds what individuals feel, believes and likes over facts, arguments and logics.

In the meantime, the extreme individualization and the central logic of equating visibility/popularity with legitimacy in Social Media along with the corporate algorithmic manipulation of news feeds create a fertile ground for populist perception and enclaves of like-mindedness (though not similar in all platforms) because algorithms prioritize relevance over significance. This is primarily a commercial technique designed to increase sales revenues but nevertheless they also apply to any socio-political important issue in the form of news and semiotic content as well. This is not necessarily and directly the overarching aim that the Social Media platform owners pursue but a natural side effect of their operations. The leading core principle for Social Media operation is to increase media consumption. The more users consume, engage with, and contribute to the platform the more there is added value for the platform. On the one hand, the users' use of media turns them into a member of audience for various kinds of advertisements directed at them and as such increases the value of the platform. On the other hand, any form of engagement, use, interaction, contribution, sharing content and information, linking, etc. is considered the trade currency, i.e., information to be used for commercial purposes, e.g., for more precision targeted advertising, distribution of advertising content, and various market research operations (KhosraviNik 2017b). As such, the platforms constantly seek solutions to enhance use and contributions from users. This is the guiding force for various kinds of algorithmic rearrangement of the content visible to individual users. For example, Facebook news feed of every individual is catered around the 'knowledge' that the platform has already gathered on the user (through their entire digital consumptions on all gadgets and platforms) and the predictions it can make about their political views, interests, issues, vulnerabilities, belief systems, etc. As such, the platform works based on the principle of relevance rather than significance. That is, the platform shows the user what it predicts to be liked/enjoyed by the user rather than following a public service logic of delivering news to public in terms of reflecting the world out there to the whole public, i.e., media as the fourth estate. By taking into account the dominant affective mode of communication, like-minded users would predominantly see each other's reactions, news, links, commentaries; a process which would lead to echo chambers and intensification of the belief systems. All forms of interactions on Social Media function as a form of promotion of that content. Whether it is 'liking' or 'commenting' or 'sharing' or 'tagging' they all help that content to become more important and get more exposure so it is 
natural if we avoid engaging with views that we do not like/approve. In other words, there is a technological design with a consequence of eco chambers. This is also due to dominance of economic logic on digital spaces; otherwise, the participatory web could alternatively be used as public sphere for deliberation or expression of suppressed identities. In line with affective impetus of popularity and legitimacy building, digital enclaves of like-mindedness are not about new ideas of (critical) perspective, they are about how well or effectively group members reiterate the same idea/belief. Hence, the result is intensification of opinions at best, which partly explains the fake new phenomenon. Algorithmic manipulations types 'range from purposes as mundane as deciding the color of a button, to decisions as significant as which news article is shown to the public. These decisions are in increasingly central to social, political and civic processes' (Tufekci 2015: 205). They are gatekeepers but they are different from their offline, non-interactive and noncomputational counterparts, e.g., in newspapers. In mass media, there is subjectivity and human factor and obviously possible manipulation. Ideology is there but it is not automatic and can be attributed to certain (powerful) groups of people (e.g., what van Dijk refers to as 'symbolic elites') who can be held accountable for decisions they make. This process is automatic and (arguably) a non-human operation in digital media. There is no human subjectivity at the local levels of operation but the entire operation is geared towards enhancement of consumption (of Social Media) and increasing the contribution of users to the platforms. This is apart from the paid-for adverting that is becoming increasing common on Social Media as well.

There is also the fact that Social Media technologies do not recognize society as a collective public out there unless through their own frame of publics of digital prosumers. While in mass media operations, everybody gets the same product (news, shows, films, etc.); Social Media shows different things to different users. There is no easy way to research the final product, i.e., representation of the world in Social Media as it is individually catered for. In similar vein, the research shows that the general public is not sufficiently aware of the quality and extent of such individually tailored representations on participatory web and in cases they do, there is little that they can imagine about it. Algorithmic manipulations are nothing short of new forms of gate-keeping operations with integral consequences in construction of representational realities, i.e., discourses among users. Algorithmic gate-keeping is the process by which 'such nontransparent algorithmic computation tools dynamically filter, highlight, suppress, or otherwise play an editorial role-fully or partially - in determining: information flows through online platforms and similar media' among other effects (Tufekci 2015: 208).

The algorithmic surveillance of Social Media is not an ideological machine in traditional sense, i.e., it is mainly automatic and machine controlled whereby human factor does not normally interfere with the regimentation. Algorithms are able to act as stealthy, extremely potent gatekeepers unaccompanied by transparency and visibility (Tufekci 2015: 209). Algorithmic data and interpretation can now understand information which might have not been openly disclosed, e.g., sexual orientation, ethnicity, religious and political views, personality traits, intelligence, happiness, use of addictive substance, parental separation, age, and gender and a lot 
other aspects (ibid: 210). Algorithms shape the perception of the world out there for users along the lines of what they assume is beneficial for the platform commercial goals.

The dynamic of discursive power, i.e., snowball effect of discourse foci, is unpredictable on Social Media communicative paradigm (KhosraviNik 2014, 2017b). The guiding strategy in Social Media design is to loop back users' digital behaviors and reactions in a way that statistics and volume of interactions, e.g., 'likes', 'comments', 'sharing', etc. are used to populate certain topics, texts, sites, or news items. This is why Social Media phenomena expand exponentially and swiftly. Throughout this process, there is no in-built fact checking mechanism. In other words, certain news, which may have come to dominate the web, can easily be false or intentionally fabricated for certain political impact. Social Media are about visibility/popularity not facts. They do not have the design capacity with regard to veracity of the content. In fact, as far as the dominant rational of Social Media are concerned, there is no logical incentive or sensible room for integration of such concerns into the technological design. Yet there is an unprecedented accumulation of discursive power in such technological regimentation of content. The current design rules out factuality in favor of resonance with audiences; hence, there is a strong digital nudge for users/ordinary members of the public to automatically equate visibility/popularity of a piece of news to its creditability. This is the very essence of an epistemological shift brought about by the triumph and hyper-normalization of market logic of exchange value. The essence of Social Media is creditability gained by visibility/popularity in a context where popularity results in commercial gains regardless of the consequences. This is about extending commercial domain logic, i.e., higher demand is higher value to sphere of politics, which could amount to disastrous results. In other words, Social Media could actually function as spaces for democratic practice, but the dominance of commercial rationality has diminished this potential and, in many ways, destroyed this capacity. Obviously, these effects are different in different Social Media platforms, e.g., compare Facebook with Twitter but nevertheless, the central logic of corporatized participatory web is the same. Once again this is about colonization of what could be appropriated as new public sphere by corporate forces and a digital version of market economy, which is plaguing the ideal potential of the new media spaces. This is the same force, which is an increasing threat to traditional mass media as well.

The New Media technology literature is full of undertones of claims to postideological era, partly coming from media deterministic understanding and partly impacted by new psychological approaches. In many trends of thoughts notions like ideology, discourse and representations are cast aside as being irrelevant in the study of New Media technology. However, the claim to post-ideology is already a strictly ideological stance at its core. In most cases, this is about assuming the triumph of market economy and neo-liberalism over all aspects of social and personal life including media technologies. Post-ideology thesis in the meantime trivializes the democratic struggles and values in a way that the whole democratization project is deliberately and misleadingly reduced to forms of direct opinion gathering mechanism. This simplified understanding of democracy reduces it to 
merely a polling mechanism and disregards the requirements of systems of checks and balances, liberal civil laws, civil society apparatus, fourth estate media etc., which are part and parcel of the original democratic thought and enlightenment. In many ways, Social Media sensations are inherently populist phenomenon. This is not a problem in and by itself but the permeation of the principle of visibilityequals-legitimacy and the claim that Social Media are empowering the voiceless can have counterparts in structural politics of populism in which the populists predominately make anti-establishment claims, disregard for norms and values inherent in democracies and usually make pledges to overthrow the system in the benefit of 'the real people'. The problem is not in the practice; it is about the philosophical essence that Social Media implicitly push forward. You could argue that democracy is about gaining popularity which is right but the point always missed is that democracy is not just about gaining popularity, it is about having a viable apparatus for rational argumentation and expression of all ideas, e.g., a healthy civic media system. It is about having systems of fact checking and accountability, division of powers, anchorage to central civil principles, etc. Social Media seem to have removed all requirements of democracy and dangerously reduced it to a participatory reality TV. In that sense, Social Media politics has created a fertile space of growth of populist politics or a form of haphazard populist ground in every sense. Trump performance in the US is a prime example of this trend both in terms of the content of his discourse as well as the centrality of Social Media practice in his operation.

Social Media are characterized as the realm of affects, connections and personal sharing. In turn, it is argued that it is now the age of affective (rather than deliberative) politics, i.e., the age of prioritizing feelings over facts. It is the age where rationality takes a back seat in favor of relationality. New digital media are not the cause of this turn. There are sociological and cultural reasons for populist tendencies in the west and indeed around the globe. There are wider ontological shifts in politics and the world imaginary, which have caused this turn. Social Media are both the product and at the same time perpetuator of such preference. That is why their guiding logic resonates with contemporary people. Social Media at the age of behavioral adverting are the epitome of preference of relevance over significance. Social Media are about your life, what you like, what you feel and they cater towards what you prefer by constantly monitoring your online behavior. This is of course done to maximize profit through targeted adverting and promotions. Social Media do not show you the world out there, they construct a world to your liking and as such they are breeding ground for echo chambers, and constructions of filter bubbles where all like-minded people get together and reinforce their own perception of the realities and priorities rather than engaging with other views. Having said all the above, this is wrong to assume that Social Media have had a causal effect on the shift to right wing populism. Politics is primarily about the society, its internal struggles and shifts in social contexts. Any analysis of role of media in politics is primarily instituted in society. Technologies of communication are also part of this social context as well-being means of political discourse and practice. In the same vein, the rise of right wing populism (i.e., the support from the underclass) is basically a protest against normalization of neo-liberal economy, 
economic globalization, pursuit of growth, disregarding issues around distribution of wealth and the constant normalization of such practices, which has constituted a democratic deficit in the west. Yet, the political impact of techno-discursive design of media in general and Social Media in particular should be considered in this equation, not the least in terms of their mutual impact. Algorithms are ideologically laden systems, which work with a normalized market logic in line with the increasing corporatization of digital platforms. Algorithms may not care about the politics per se but they do have a political impact in the way they regiment the content for users and general public. Computer systems are not automatic and free from ideology in their design. They are deliberately organized around a form of digital market economic perspective, e.g., a misconstrued interpretation of gift economy through the processes of playbour and digital labour (Fuchs 2014) but at the same time making claims to empowerment of ordinary people and democratizing of access to symbolic and representational resources and identity performances. In pursuing that they have interest in projecting a post-political facade. Research approaches in media and technology and waves of research influenced by affect theory with their psychological overtone seem to work on propagated assumptions that envisage the society devoid of the classic political struggles. What remains is that as far as the critical and socially oriented commitment of research is taken into account, e.g., in Social Media critical discourse studies, contextualization of research cannot do without notions of power, and discourse. It is very evident that affective aspect is a crucially relevant aspect of research on Social Media. In other words, new approaches in critical discourse analysis should meaningfully engage with these aspects and literature. However, it remains unclear how an epistemological and ontological neutralization of approaches in critical media studies would be a step forward in the field. On the other hand, it is one thing to acknowledge that the affective side of communication has always been part of human communication and one of the important features in persuasion and discourse studies, but it is another thing to aspire to explain the turn to post-rationality and pot-deliberation as step forward in western understanding of polity and democratic understanding.

Open Access This article is distributed under the terms of the Creative Commons Attribution 4.0 International License (http://creativecommons.org/licenses/by/4.0/), which permits unrestricted use, distribution, and reproduction in any medium, provided you give appropriate credit to the original author(s) and the source, provide a link to the Creative Commons license, and indicate if changes were made.

\section{References}

Ahmed, S. 2014. The cultural politics of emotions. Edinburgh: Edinburgh University Press.

Boyd, D. 2008. Can social network sites enable political action? In Rebooting America, ed. A. Fine, M.

Sifry, A. Rasiej, and J. Levy, 112-116. Mountain View: Creative Commons.

Castells, M. 2009. Communication power. Oxford, NY: Oxford University Press.

Copsey, N. 2003. Extremism on the net: The extreme right and the value of the internet. In Political parties and the internet: Net gain?, ed. R. Gibson, P. Nixon, and S. Ward, 218-233. London: Routledge.

Couldry, N. 2012. Media, society, world: Social theory and digital media. Cambridge: Polity Press.

Fuchs, C. 2014. Social media: A critical introduction. London: Sage. 
KhosraviNik, M. 2010. Actor descriptions, action attributions, and argumentation: Towards a systematization of CDA analytical categories in the representation of social groups. Critical Discourse Studies 7 (1): 55-72.

KhosraviNik, M. 2014. Critical discourse analysis, power and new media discourse. In Why discourse matters: Negotiating identity in the mediatized world, ed. Y. Kalyango, and M.W. Kopytowska, 287-306. New York: Peter Lang.

KhosraviNik, M. 2015a. Discourse, identity and legitimacy: Self and other in representations of Iran's nuclear programme. Discourse approaches towards politics, society and culture (DAPSAC). Amsterdam: John Benjamins.

KhosraviNik, M. 2015b. Macro and micro legitimation in discourse on Iran's nuclear programme: The case of Iranian national newspaper Kayhan. Discourse and Society 26 (1): 52-73.

KhosraviNik, M. 2017a. Right wing populism in the west: Social media discourse and echo chambers. Insight Turkey 19 (3): 53-68.

KhosraviNik, M. 2017b. Social media critical discourse studies (SM-CDS). In Routledge handbook of critical discourse studies, ed. J. Flowerdew, and J. Richardson, 582-598. London: Routledge.

KhosraviNik, M., and M. Zia. 2014. Persian nationalism, identity and anti-Arab sentiments in Iranian Facebook discourses: Critical discourse analysis and social media communication. Journal of Language and Politics 13 (4): 755-780.

KhosraviNik, M., and J. Unger. 2016. Critical discourse studies and social media: Power, resistance and critique in changing media ecologies. In Methods of critical discourse studies, $3 \mathrm{rd} \mathrm{ed,} \mathrm{ed.} \mathrm{R.} \mathrm{Wodak,}$ and M. Meyers, 205-233. London: Sage.

KhosraviNik, M., and N. Sarkhoh. 2017. Arabism and anti-Persian sentiments on participatory web platforms: A social media critical discourse study. International Journal of Communication 11: 3614-3633.

KhosraviNik, M., and D. Kelsey. forthcoming. Participatory web, discourse and politics. London: Bloomsbury.

Marsdal, M. 2013. Loud values, muffled interests? Third way social democracy and right wing populism. In Right wing populism in Europe: Politics and discourse, ed. R. Wodak, M. KhosraviNik, and B. Mral, 39-54. London: Bloomsbury.

Papacharissi, Z. 2015. Affective publics: Sentiment, technology, and politics. Oxford: Oxford University Press.

Pedwell, C. 2014. Affective relations: The transnational politics of empathy. Basingstoke: Palgrave.

Reisigl, M., and R. Wodak. 2016. The discourse-historical approach (DHA). In Methods of critical discourse studies, 3rd ed, ed. R. Wodak, and M. Meyer. London: Sage.

Richardson, J. 2013. Ploughing the same furrow? Continuity and change on Britain's extreme right fringe. In Right wing populism in Europe: Politics and discourse, ed. R. Wodak, M. KhosraviNik, and B. Mral, 105-120. London: Bloomsbury.

Ritzer and Jurgenson. 2010. Production, consumption, prosumption: The nature of capitalism in the age of the digital 'prosumer'. Journal of Consumer Culture 10 (1): 13-36.

Tufekci, Z. 2015. Algorithmic harms beyond Facebook and Google: Emergent challenges of computational agency. Journal on Telecommunication \& High Technology Law 13: 203-445.

Unger, J., R. Wodak, and M. KhosraviNik. 2016. Critical discourse studies and social media data. In Qualitative research, 4th ed, ed. D. Silverman, 277-293. London: Sage.

Wetherell, M. 2012. Affect and emotion. London: Sage.

Wodak, R., and M. KhosraviNik. 2013. Dynamics of discourse and politics in right wing populism in Europe and beyond: An introduction. In Right-wing populism in Europe, politics and discourse, ed. R. Wodak, M. KhosraviNik, and B. Mral. London: Bloomsbury.

Wodak, R., M. KhosraviNik, and B. Mral (eds.). 2013. Right-wing populism in Europe: Politics and discourse. London: Bloomsbury Academics.

Wodak, R., and M. Meyer (eds.). 2016. Methods of critical discourse studies, 3rd ed. London: Sage.

Zayani, M. 2015. Networked publics and digital contention: The politics of everyday life in Tunisia. New York: Oxford University Press.

Majid KhosraviNik is Senior Lecturer in Digital Media and Discourse Studies at Newcastle University. He teaches modules on Digital Discourses and Identity and Politics, Power and Communication at the School of Arts \& Cultures while supervising a number of doctoral and post-doctoral projects. He has 
published widely on critical discourse studies including immigration discourses, self and other representation, national identity, right wing populism, and regional identities in the Middle East. He is specifically interested in digital media discursive practices in global contexts. Majid researches the intersection of participatory web, discourse and politics by investigating the impact, dynamic and challenges of Social Media technologies within a Social Media Critical Discourse Studies (SM-CDS) model. Majid is a founder of Newcastle Critical Discourse Studies, sits on editorial board of Critical Discourse Studies (Routledge) and Journal of Language \& Politics (John Benjamins) while acting as an expert evaluator and moderator for a range of international publishers and research grant organisations including the EU commission. 